\title{
Algunas consideraciones sobre la inmigración de magrebíes en España y su incierto futuro
}

\author{
M. PILAR González YANCI *
}

\section{INTRODUCCIÓN}

En recientes publicaciones de organismos como la OCDE o Population Action International, se pone de manifiesto el peso que hoy tiene en los flujos migratorios mundiales el que suele denominarse Sur-Norte, de los países en desarrollo (developing countries) a los industrializados (figura 1). Europa, junto a América del Norte, son los dos grandes receptores de este flujo, que, desde 1985, ha conocido una serie de cambios, como la di-

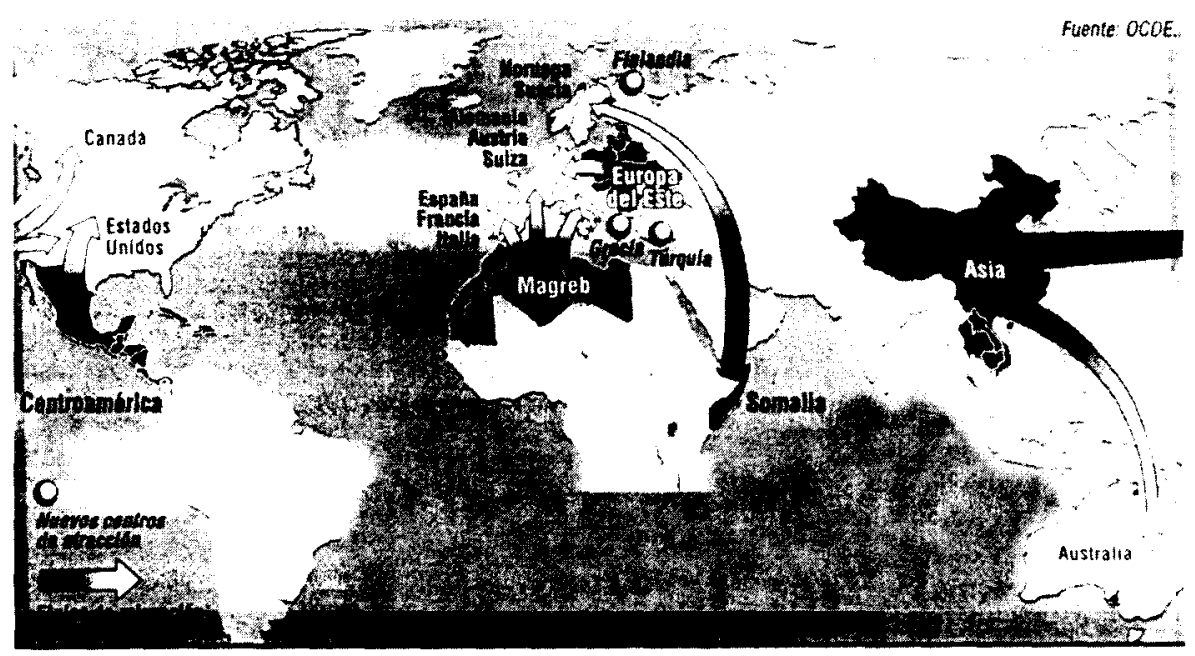

Figura 1. Movimientos migratorios en 1991-1992.

* UNED, Madrid. 
versificación del origen, dando cabida a un mayor número de asiáticos, junto a los tradicionales africanos, y la aparición en el destino de nuevos países de acogida, que antes eran emigrantes, como España e Italia. Efectivamente, en el panorama actual de la inmigración en España, tiene un peso relevante la que procede del Norte de Africa, e incluso del Africa subsahariana, incluyendo países como Nigeria. Sobre algunas de sus características y su posible evolución vamos, en este artículo, a hacer algunas breves consideraciones.

\section{EVOLUCIÓN Y CARACTERISTICAS DE LA INMIGRACIÓN PROCEDENTE DEL MAGREB}

El Magreb envía, desde hace muchos años, notables contingentes de emigrantes a varios países europeos, en clara relación con el pasado coIonial. Durante las Guerras Mundiales salieron muchos argelinos a Francia, unos como mano de obra a reemplazar a los franceses en el frente y otros reclutados con fines militares. Después de la reconstrucción de nuevo se abriría una corriente, que había quedado interrumpida y que no ha cesado de aumentar. En España las cosas ocurrieron de manera diferente. No obstante la proximidad física, en los tiempos recientes el estrecho de Gibraltar no fue testigo de grandes desplazamientos. Hubo, sí, una corriente que desde España enviaba hombres jóvenes, expulsados de un campo con graves dificultades, a Orán y Argel, donde llegaron a constituir un grupo importante, que en 1900 era de 160.000 personas y que, en buena parte, no vió cumplido su deseo de retornar, a pesar de ser el proyecto inicial.

En sentido inverso no hay grandes movimientos. España realizó una tarea de colonización en su zona de protectorado, con gran esfuerzo, pero que no caló profundamente $y$, desde luego, no dió lugar a una corriente migratoria. En los Censos españoles de 1900 a 1930 se registraban cifras de marroquíes en aumento, instalados, sobre todo, en las plazas y provincias africanas y en las más próximas de Cádiz, Málaga y Sevilla (cuadro 1). Después de la Guerra Civil sólo fue importante la llegada de marroquíes, precisamente a las ciudades de Ceuta y Melilla, donde se registra la mayor afluencia entre 1940 y 1974 , como se puso de manifiesto en el censo extraordinario de 1987 llevado a cabo en dichas ciudades para obtener información sobre esta población, a la que apenas se habia considerado antes. 
CUADRO 1. MARROQUÍES CENSADOS EN ESPAÑA. 1900-1930

\begin{tabular}{rrrrccr}
\hline CENSO & HOMBRES & MUJERES & TOTAL & $\begin{array}{c}\text { \% DEL TOTAL } \\
\text { EXTRAN. }\end{array}$ & $\begin{array}{c}\text { EN N Y W } \\
\text { DE AFRICA }\end{array}$ & $\begin{array}{c}\text { EN } \\
\text { PENINSULA }\end{array}$ \\
\hline 1900 & 465 & 270 & 735 & 1,3 & 328 & 407 \\
1910 & 1.812 & 916 & 2.728 & 4,4 & 1.791 & 937 \\
1920 & 2.603 & 1.433 & 4.036 & 3,2 & 1.757 & 2.279 \\
1930 & 4.569 & 2.232 & 6.801 & 4,1 & 5.429 & 1.372 \\
\hline
\end{tabular}

Fuente: Censo

No es de extrañar que no se prestara mucha atención al fenómeno, puesto que en los años sesenta era el momento en que España se insertaba en el flujo migratorio predominante en aquel momento, pero como país emisor, que enviaba asalariados hacia los países más industrializados de Europa, junto a los que acudían desde el Magreb y desde otros países del Mediterráneo europeo. El cuadro 2 pone de relieve el contraste entre las cifras de magrebies en España y Francia por estos años. La independencia lograda por los países árabes llegó unida a una fuerte evasión de capitales, con el consiguiente cierre de empresas y el natural impulso a la emigración de una gran parte de la población, que encontraba trabajo, fácilmente, en las prósperas economias europeas.

CUADRO 2A. MARROQUÍES EN ESPAÑA

\begin{tabular}{cccccc}
\hline AÑO & NUMMERO & $\%(1)$ & AÑO & NÚMERO & $\%(1)$ \\
\hline 1964 & 410 & 0,4 & 1970 & 1.710 & 1,1 \\
1965 & 663 & 0,7 & 1971 & 1.860 & 1,2 \\
1966 & 825 & 0,7 & 1972 & 1.960 & 1,2 \\
1967 & 993 & 0,8 & 1973 & 2.198 & 1,3 \\
1968 & 1.188 & 0,9 & 1974 & 2.308 & 1,4 \\
1969 & 1.472 & 1,0 & 1975 & 2.277 & 1,4 \\
\hline
\end{tabular}

(1) respecto al total de extranjeros

Fuente: I.N.E. e INSEE

CUADRO 2B. MAGREBÍES EN FRANCIA

\begin{tabular}{ccrr}
\hline AÑO & ARGELINOS & MARROQUIES & TUNECINOS \\
\hline 1954 & 211.675 & 10.734 & 4.800 \\
1962 & 350.484 & 33.320 & 26.569 \\
1968 & 473.812 & 84.236 & 61.028 \\
1975 & 710.690 & 260.025 & 139.735 \\
\hline
\end{tabular}


Esta situación se mantuvo hasta la década de los años setenta, cuando la crisis del 73 va a marcar el inicio de una nueva etapa. La aparición del fantasma del paro, como una de las consecuencias de la crisis y, de otro lado, los progresos de las modernas tecnologias, con sus repercusiones sobre el empleo de mano de obra no cualificada, van a incidir en la emigración. Los grandes receptores, ante el temor de ver definitivamente asentada a la población inmigrante, joven, expansiva, y hasta reivindicativa, en sus envejecidas sociedades, comienzan a tomar medidas para obstaculizar la entrada y permanencia de extranjeros. En este contexto, en cambio, España comienza su despegue económico y entra en la órbita de los países industrializados y hasta pasa a pertenecer a la entonces C.E.E.

Este será el momento en que se da el gran cambio, con la reducción de la emigración de españoles, el comienzo del retorno de los que habían salido y el cese del gran éxodo rural. Desde entonces, un número creciente de emigrantes, que se dirigian a los tradicionales receptores europeos, al encontrar el freno de las nuevas políticas restrictivas, que se van implantando, se desvía a España, uniéndose a otras corrientes de emigrantes de sus antiguas colonias (América Latina, Guinea...). De esta forma, a partir de los años ochenta (figura 2) comienza a ser importante la llegada a España

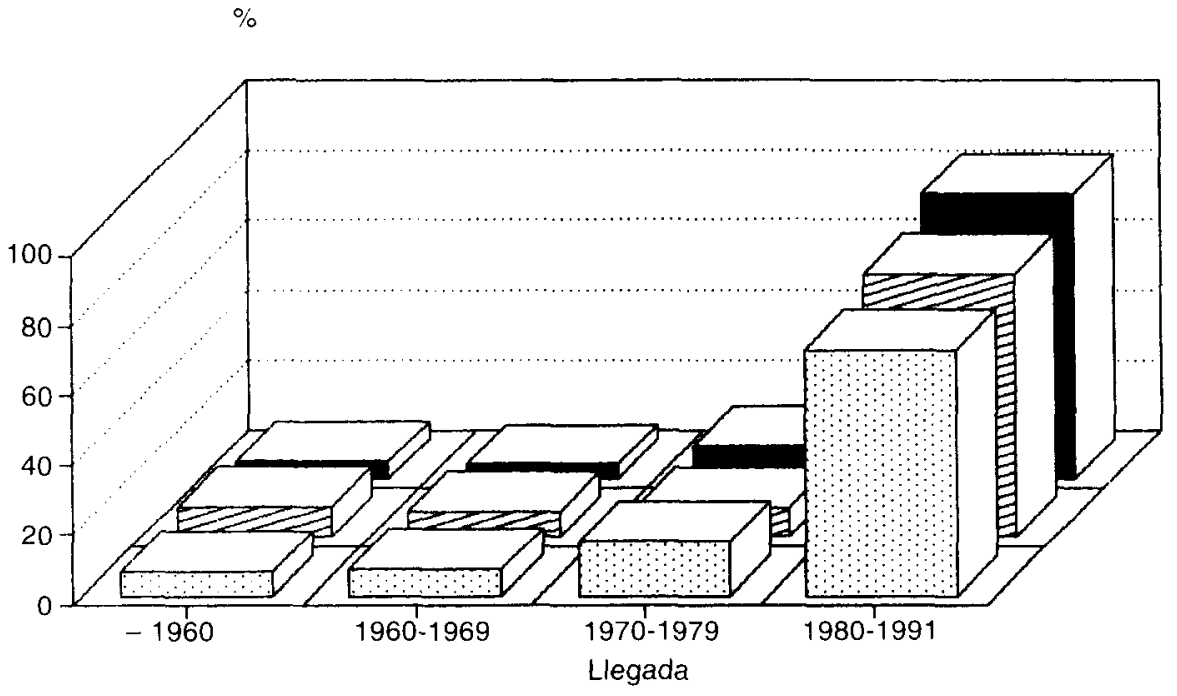

Marruecos $\quad$ Argelia Túnez

Figura 2. Fecha de llegada de magrebies a España. Censo 1991. 
de inmigrantes, en general, y del Magreb, y más exactamente de Marruecos, en particular, llegando a constituir hoy una colonia importante y en expansión, formada, mayoritariamente, por marroquíes y en la que, los argelinos van experimentando un importante incremento (cuadro 3).

CUADRO 3. MAGREBÍES RESIDENTES EN ESPAÑA 1966-1993

\begin{tabular}{|c|c|c|c|c|c|}
\hline AÑO & MARRUECOS & ARGELIA & TÚNEZ & TOTAL & $\%(1)$ \\
\hline 1966 & 813 & 14 & 9 & 836 & 0,76 \\
\hline 1967 & 982 & 25 & 10 & 1.017 & 0,83 \\
\hline 1968 & 1.156 & 33 & 14 & 1.203 & 0,92 \\
\hline 1969 & 1.445 & 50 & 22 & 1.517 & 1,09 \\
\hline 1970 & 1.695 & 55 & 26 & 1.776 & 1,20 \\
\hline 1971 & 1.841 & 54 & 26 & 1.921 & 1,24 \\
\hline 1972 & 1.954 & 58 & 24 & 2.036 & 1,28 \\
\hline 1973 & 2.191 & 62 & 25 & 2.278 & 1,38 \\
\hline 1974 & 2.233 & 78 & 24 & 2.432 & 1,46 \\
\hline 1975 & 2.264 & 94 & 30 & 2.388 & 1,44 \\
\hline 1976 & 2.157 & 93 & 35 & 2.285 & 1,43 \\
\hline 1977 & 2.134 & 101 & 40 & 2.275 & 1,40 \\
\hline 1978 & 2.066 & 106 & 39 & 2.211 & 1,39 \\
\hline 1979 & 2.557 & 133 & 47 & 2.737 & 1,58 \\
\hline 1980 & 2.898 & 180 & 101 & 3.179 & 1,75 \\
\hline 1981 & 3.596 & 226 & 65 & 3.887 & 1,96 \\
\hline 1982 & 3.765 & 278 & 57 & 4.100 & 2,04 \\
\hline 1983 & 4.139 & 281 & 63 & 4.483 & 2,13 \\
\hline 1984 & 5.172 & 337 & 107 & 5.616 & 2,47 \\
\hline 1985 & 5.738 & 363 & 88 & 6.268 & 2,59 \\
\hline 1986 & 8.738 & 441 & 132 & 9.311 & 3,17 \\
\hline 1987 & 11.152 & 523 & 155 & 11.830 & 3,53 \\
\hline 1988 & 11.896 & 559 & 255 & 12.710 & 3,54 \\
\hline 1989 & 14.024 & 675 & 291 & 14.990 & 3,76 \\
\hline 1990 & 16.665 & 702 & 262 & 17.629 & 4,32 \\
\hline 1991 & 31.890 & 2.405 & 348 & 34.643 & 9,80 \\
\hline
\end{tabular}

(1) respecto al total de extranjeros

Conocer a fondo la realidad de esta inmigración no es tarea fácil, por múltiples motivos: la dificultad de acceder a las numerosas fuentes que nos brindan información, la propia movilidad del fenómeno, que hace que los datos sean obsoletos en muy poco tiempo, la certeza de que es elevado el número de clandestinos que no alcanzan la legalización o que, tras obtenerla, la pierden, son algunos de aquéllos. No obstante, entre las consideraciones que aqui estamos realizando, resulta oportuno hacer un comentario de las características de los inmigrantes magrebies, que hoy constituyen en España el grupo de los que están en situación regular, sin 
pretender un estudio profundo. Los datos más actualizados del Ministerio de Trabajo nos presentan el conjunto de los que poseen un permiso de trabajo. El cuadro 4 nos permite analizar y comparar por paises las características de edad, sexo y tipo de permiso de trabajo de la población activa magrebí. Destaca, en primer lugar, lo exiguo del número de mujeres que obtienen permiso de trabajo, que en el caso de los argelinos no alcanza ni el $5 \%$. Esto se explica fácilmente por dos razones. En primer lugar estamos ante una inmigración que moviliza sobre todo a varones, pero además, las mujeres que acuden con sus familias, que son numerosas, apenas trabajan fuera del hogar, dado que en la cultura musulmana ésto no se acepta fácilmente.

CUADRO 4. CARACTERÍSTICAS DE EDAD, SEXO Y CLASE DE PERMISO DE TRABAJO. 31-XII-1993

\begin{tabular}{crrrrrr} 
& \multicolumn{2}{c}{ MARRUECOS } & \multicolumn{2}{c}{ ARGELIA } & \multicolumn{2}{c}{ TÚNEZ } \\
& \multicolumn{1}{c}{ TOTAL } & \multicolumn{1}{c}{$\%$} & \multicolumn{1}{c}{ TOTAL } & \multicolumn{1}{c}{ TOTAL } & $\%$ \\
\hline$H$ & 36.981 & 85,2 & 2.082 & 95,8 & 127 & 82,5 \\
$M$ & 6.437 & 14,8 & 92 & 4,2 & 27 & 17,5 \\
-20 años & 628 & 1,4 & 14 & 0,6 & - & - \\
$20-24$ & 6.034 & 13,9 & 383 & 17,6 & 10 & 6,5 \\
$25-54$ & 35.409 & 81,5 & 1.764 & 81,1 & 140 & 90,9 \\
55 y más & 1.347 & 3,1 & 13 & 0,6 & 4 & 2,6 \\
permiso inicial & & & & & & \\
y de 1 año & 4.947 & 11,4 & 133 & 6,1 & 22 & 14,3 \\
renovación & 32.103 & 73,9 & 1.983 & 91,2 & 107 & 69,5 \\
perm. 5 años & 5.249 & 12,1 & 58 & 2,7 & 25 & 16,2 \\
permiso fronterizo & 1.119 & 2,6 & - & - & - & - \\
\hline
\end{tabular}

Fuente: Ministerio de Trabajo

Por tanto, resulta sorprendente el casi $15 \%$ de permisos a mujeres con que cuenta actualmente Marruecos. Si se compara con 1989 este porcentaje se ha elevado en mas de un punto (en aquel año era 13,5\%). Este hecho se relaciona con lo que algunos han llamado una "femeneización" de la emigración árabe. Además hay que tener en cuenta que se está produciendo el hecho de que, al ser difíciles las condiciones para encontrar trabajo, es cada día mayor el número de hombres que aceptan que sus mujeres trabajen, a condición, la mayoria de las veces, de que sea en una casa (servicio doméstico), que es, por otro lado, uno de los sectores donde es más fácil encontrar empleo. 
En segundo lugar, se aprecia que se trata de una población joven en todos los casos. Entre los marroquíes y argelinos los menores de 24 años son más del $15 \%$. Como es natural, la mayoría de todos los grupos se incluyen en el tramo de edades de 25 a 54 años y son muy pocos los de más de 55.

Por último, es de destacar que se trata de una población que obtiene permiso por ciclo corto, normalmente un año, que va renovando, siendo muy bajo el porcentaje de los que ya están más estabilizados y consiguen permisos de larga duración, permiso que, por otra parte, es casi sólo para marroquíes.

Del cuadro 5 podemos extraer información acerca de las características laborales de esta población. En primer lugar destaca un neto predominio de trabajadores por cuenta ajena, que en el caso de los argelinos son casi la totalidad. En cambio entre marroquíes y tunecinos (aunque estos últimos son tan pocos que tienen escasa significación) hay un volumen importante que trabajan por cuenta propia. Casi un $14 \%$ de los permisos son de este tipo. Esto es debido a la importancia de actividades como comercio ambulante que desempeñan estos grupos y también a los que se dedican a la construcción por cuenta propia, haciendo lo que se suele denominar "chapuzas".

\section{CUADRO 5. CARACTERÍSTICAS LABORALES DE LOS INMIGRANTES} DEL MAGREB. 31-XII-1993

\begin{tabular}{|c|c|c|c|c|c|c|}
\hline & \multicolumn{2}{|c|}{ MARRUECOS } & \multicolumn{2}{|c|}{ ARGELIA } & \multirow{2}{*}{\multicolumn{2}{|c|}{$\begin{array}{l}\text { TÚNEZ } \\
\text { TOTAL }\end{array}$}} \\
\hline & TOTAL & $\%$ & TOTAL & $\%$ & & $\%$ \\
\hline C. propia & 6.051 & 13,9 & 72 & 3,3 & 21 & 13,6 \\
\hline C. ajena & 37.367 & 86,1 & 2.102 & 96,7 & 133 & 86,4 \\
\hline S. agrario & 10.722 & 24,7 & 861 & 39,6 & 18 & 11,7 \\
\hline Industria & 4.122 & 9,5 & 332 & 15,3 & 15 & 9,7 \\
\hline Construcción & 9.383 & 21,6 & 273 & 12,6 & 8 & 5,2 \\
\hline Servicios & 17.425 & 40,1 & 628 & 28,9 & 112 & 72,7 \\
\hline $\begin{array}{l}\text { Prof. direc. } \\
\text { técnicos }\end{array}$ & 481 & 1,1 & 74 & 3,4 & 11 & 7,1 \\
\hline Administra. & 281 & 0,6 & 37 & 1,7 & 10 & 6,5 \\
\hline $\begin{array}{c}\text { Comerciantes y } \\
\text { vendedores }\end{array}$ & 5.096 & 11,6 & 63 & 2,9 & 21 & 13,6 \\
\hline Agricultores & 11.175 & 25,7 & 865 & 39,8 & 17 & 11,0 \\
\hline $\begin{array}{l}\text { Servicios } \\
\text { personales }\end{array}$ & 10.507 & 24,2 & 417 & 19,2 & 61 & 39,6 \\
\hline $\begin{array}{l}\text { Pers. indus. } \\
\text { const. trans. }\end{array}$ & 14.158 & 32,6 & 643 & 29,6 & 32 & 20,8 \\
\hline No clasif. & 1.720 & 3,9 & 75 & 3,4 & 2 & 1,3 \\
\hline
\end{tabular}

Fuente: Ministerio de Trabajo 
Respecto al sector de actividad, dado el carácter cada día más terciarizado de nuestra sociedad, hay mayoría en el de servicios, pero es de destacar que en este grupo de inmigrantes su proporción es mucho más débil que en otros. Los magrebíes, en el conjunto español, se dedican a la agricultura en un porcentaje muy superior a la de cualquier otro grupo. Los argelinos 10 hacen en casi el $40 \%$ y los marroquíes en un $25 \%$. Igualmente destaca el número de los que se dedican a la construcción, sobre todo entre los marroquíes, que casi alcanzan el $22 \%$. Esto indica claramente la posición de estos grupos en los escalones más bajos de la economía, con mínima o nula cualificación y ocupando los puestos de trabajo que mayor rechazo tienen por parte de la población española.

Esta apreciación se ratifica al observar las caracteristicas de la ocupación, donde se pone de relieve el escasísimo número de inmigrantes del Magreb que ocupa los niveles superiores de profesionales, directivos y técnicos (un 1\% de los marroquíes). Los porcentajes superiores que se observan entre argelinos y tunecinos se deben a que sus cifras son muy pequeñas y por tanto el peso de las personas más cualificadas de las embajadas y consulados es proporcionalmente más elevado. También son muy pocos los que tienen puestos de administrativos, mientras que se eleva notablemente, dentro de los que se incluyen en el terciario, el valor de aquéllos que trabajan en servicios personales y de hostelería, que son, en gran medida, trabajadores y trabajadoras del servicio doméstico, jardineros, etc.

Si atendemos a la distribución por ramas de actividad encontramos que, efectivamente, hay una mayoría dedicada al primario, en producción agrícola, ganadera y pesca, casi igualada por construcción, comercio al por menor y restaurantes, bares, hostelería y servicio doméstico, que es, por otro lado, al que se dedican la casi totalidad de las mujeres.

A partir del Censo de 1991, podemos añadir algunos datos de interés, de la población residente. Las cifras son inferiores a las de los trabajadores, pero se refieren a los grupos más asentados. Podemos destacar:

- La llegada a España se ha producido mayoritariamente, más del $70 \%$, de 1980 a 1990 (figura 2).

- Las pirámides de población son desequilibradas en el caso de los argelinos y tunecinos y mucho más equilibradas en el caso de los marroquíes, donde es muy elevado el número de familias reagrupadas (figura 3).

- Predominio claro de hombres y sobre todo jóvenes.

- Bajo nivel de instrucción, sobre todo entre los marroquíes, con casi el $50 \%$ de analfabetos y sin estudios. 
Algunas consideraciones sobre la inmigración de magrebies en España

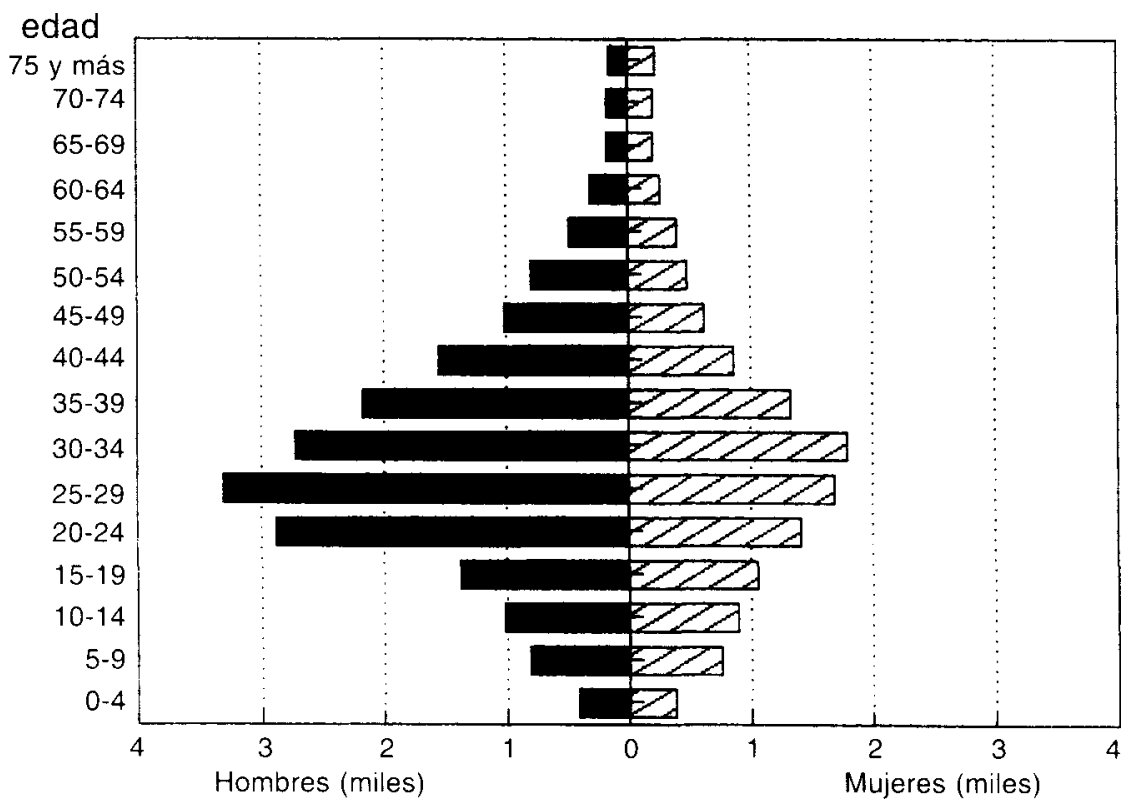

Figura 3a. Residentes marroquies en España. Censo 1991.

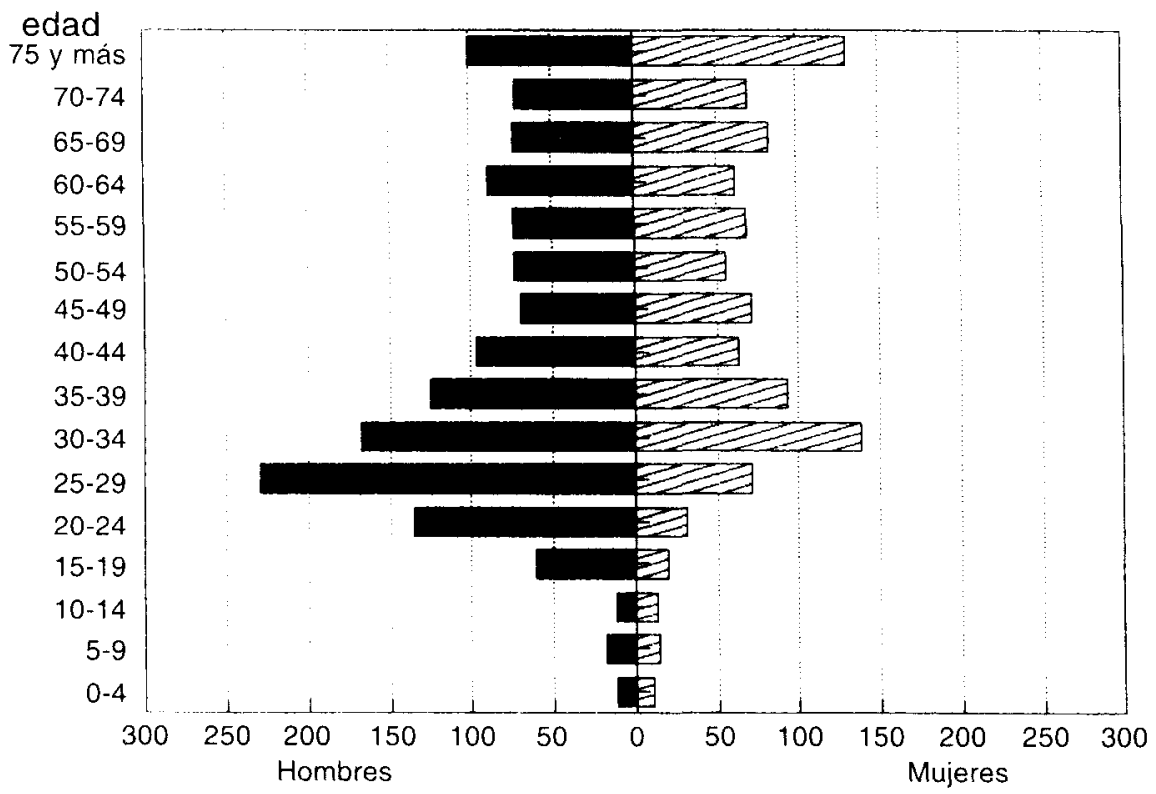

Figura 3b. Residentes argelinos en España. Censo 1991. 


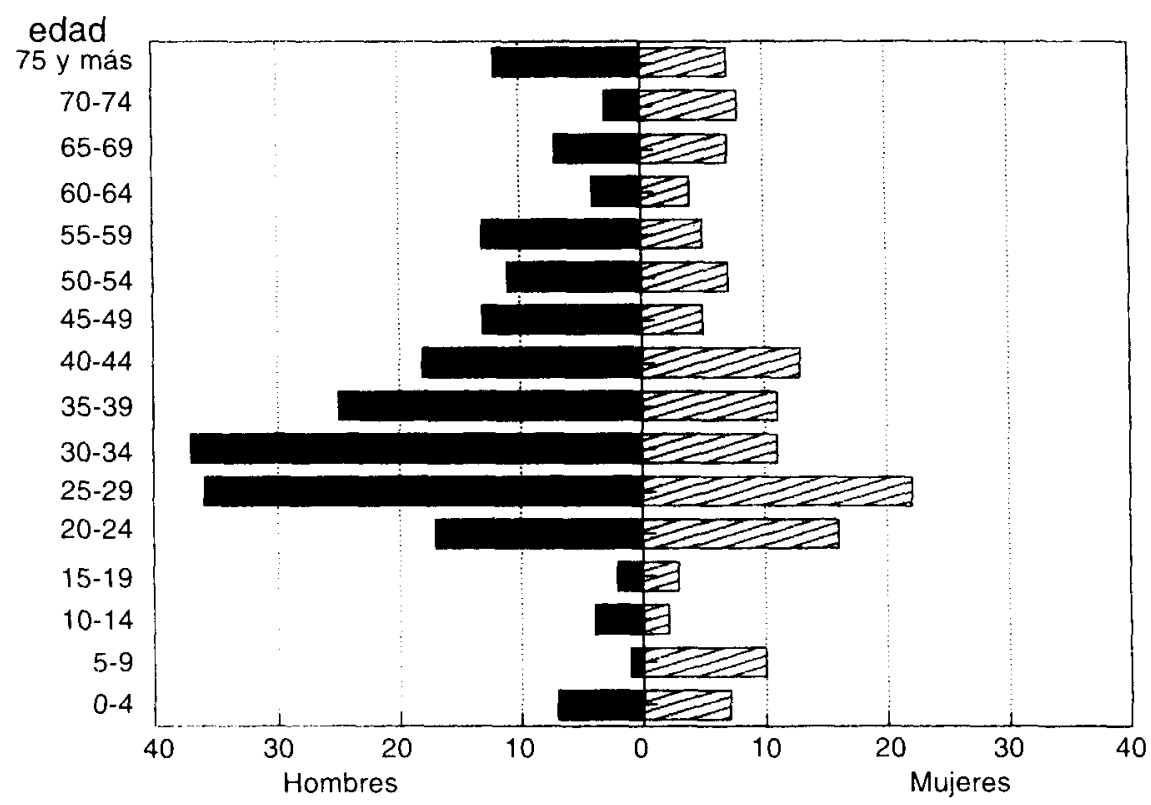

Figura 3c. Residentes tunecinos en España. Censo 1991.

- Alto porcentaje de escolarización de los hijos.

- Alta tasa de actividad y ocupación, con cifras bajas de paro. Los inactivos son casi en su totalidad las esposas e hijos (labores del hogar y escolares).

- Predominio de asalariados eventuales, no obstante ser destacable el número de empresarios sin asalariados a su cargo.

- Por profesión gran peso de los peones sin cualificación y de los empleados de comercio, hostelería, construcción (los agricultores son menos numerosos entre los residentes, más asentados)(figura 4).

- Gran peso de los que trabajan en construcción, comercio y otros servicios, salvo entre los argelinos, que tienen mayoria en agricultura, por rama de actividad (figura 5 ).

Respecto a la distribución espacial, si en los primeros tiempos los marroquies que entraban en España se establecian sobre todo en las provincias españolas del Norte de Africa y en las andaluzas más cercanas, hoy la dispersión por el territorio nacional es muy importante. No hay ninguna provincia en la que no estén representados, aunque sea con cifras bajas, como en las provincias de Avila, Palencia y Soria, donde no llegan a 20 personas. 


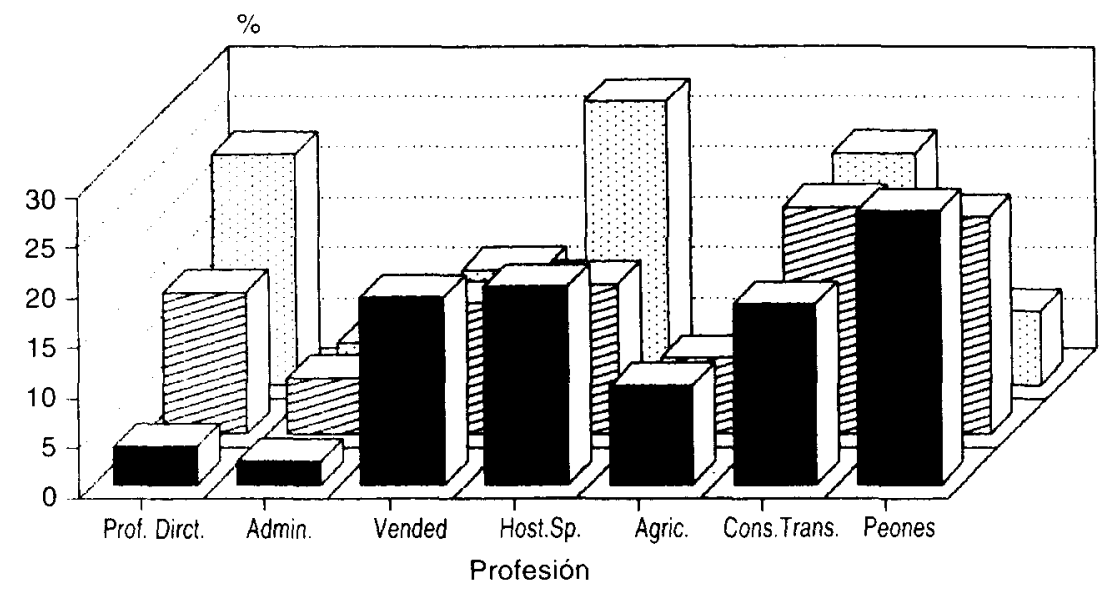

Marruecos $叉$ Argelia $\quad$ Túnez

Figura 4. Profesión inmigrantes magrebies. Censo 1991.

Su distribución viene a ser similar a la de los extranjeros en general. Son más numerosos en las comunidades de Cataluña (36\%) y Madrid $(19,5 \%)$, seguidas de Andalucía (12\%), Murcia $(9 \%)$ y C. Valenciana $(6 \%)$. Por provincias destaca su presencia en Barcelona (24\%), Madrid (19,5\%), Murcia $(9 \%)$, Gerona $(7,3 \%)$ y Málaga (4\%) (figura $6 a)$.
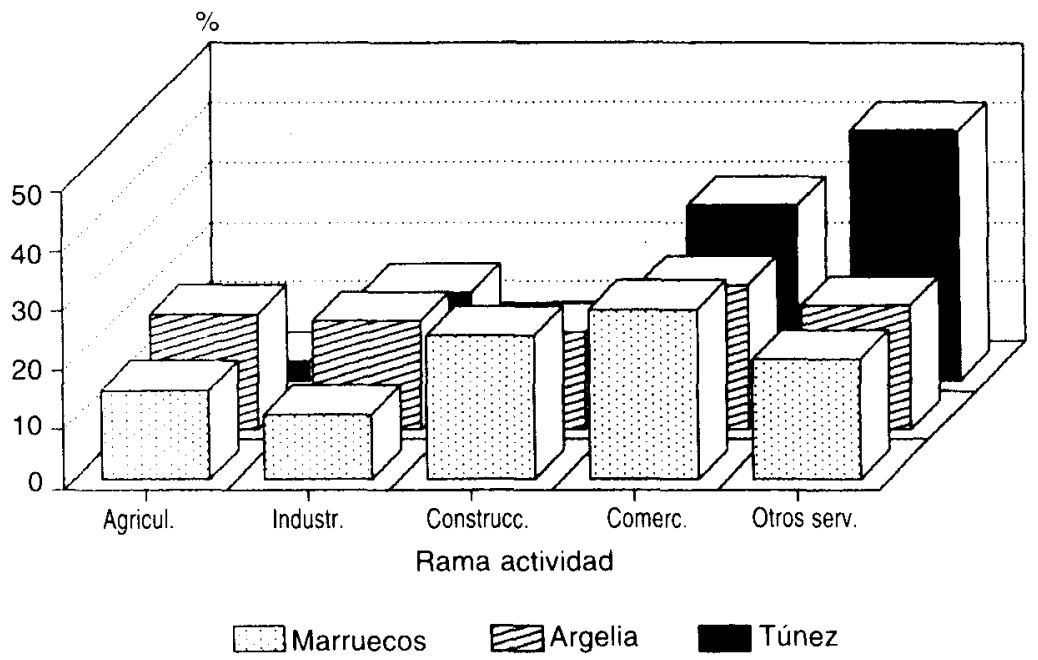

Figura 5. Rama actividad residentes magrebies. Censo 1991. 


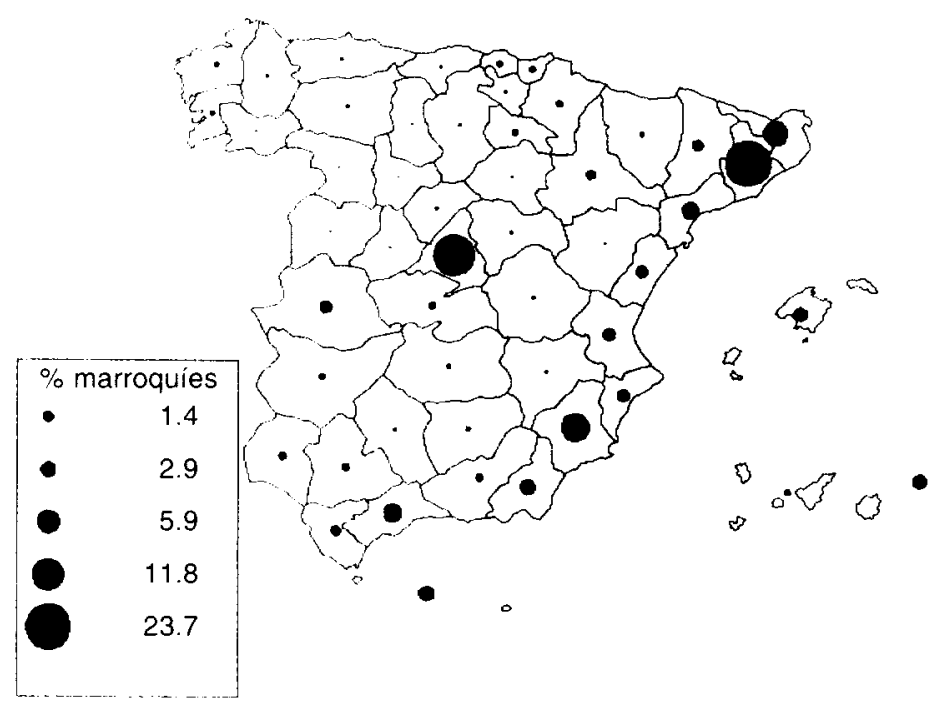

Figura 6a. Distribución trabajadores marroquies. 31-XII-1993.

En la distribución espacial juegan diversos factores. En primer lugar el dinamismo económico. Naturalmente las provincias de mayor oferta de empleo son las más receptivas, Madrid y Barcelona. Pero también juega la proximidad física, por tanto Andalucía y Levante son muy atractivas y dentro de ellas las que sean más dinámicas, con más puestos de trabajo, incluso eventuales, por poseer un potente sector turístico. En tercer lugar juega el tipo de trabajo que pueden desarrollar. Al no poseer formación para trabajar en la industria son escasos en zonas industriales como el País Vasco, donde cada vez se precisa menos mano de obra sin cualificar. En cambio, son importantes en regiones de gran actividad agraria, como Murcia, donde casi la totalidad trabaja en este sector, y en Almeria y Tarragona. En provincias como Málaga, donde el turismo es clave, la gran mayoría, casi totalidad, trabaja en el sector servicios.

Naturalmente los más cualificados, profesionales, técnicos, directivos y administrativos, que en parte trabajan en los servicios de embajadas y consulados, están básicamente en las grandes ciudades.

Los argelinos, pese a que su número es muy inferior también aparecen hoy muy dispersos, pero en este caso son bastantes las provincias en que no están representados, o sólo hay menos de 10 personas de esta nacionalidad con permiso de trabajo. Entre ellos el mayor número se da en la Comunidad Valenciana $(35,5 \%)$, Cataluña $(15 \%)$ y Aragón $(13,5 \%)$. Por provincias Valencia $(22,6 \%)$, Murcia $(11,2 \%)$, Castellón $(9 \%)$ y Almería 
$(8,5 \%)$ acogen el número más importante, mientras que Madrid y Barcelona están detrás con sólo el 5,5\% cada una de ellas (figura $6 \mathrm{~b}$ ). Los argelinos se dedican mayoritariamente al sector agrario en casi el $40 \%$, a la construcción y sector de hostelería y servicio a empresas (limpieza,etc.), siendo, en cambio muy pocos en servicios personales, en concreto doméstico. La razón está en que el número de mujeres es muy pequeño y aún es menor su acceso al mundo laboral que en el caso de las marroquíes.

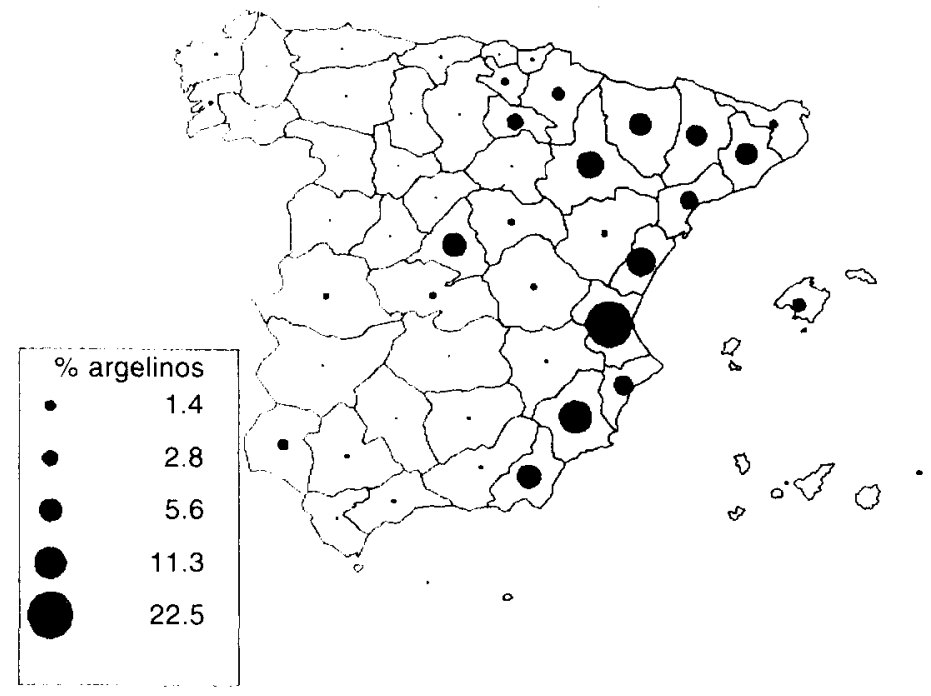

Figura 6b. Distribución trabajadores argelinos. 31-XII-1993.

Los tunecinos, cuyo número es mínimo, se concentran en Madrid (26\%) y Barcelona (16\%), en el resto, salvo en Gerona o Valencia, ni siquiera alcanzan la cifra de 10 personas (figura 6c). En cuanto a su distribución por ramas la mayoría se ocupa en restaurantes, bares y hostelería, servicio doméstico y a empresas y comercio al por menor. Son, en cambio, muy pocos en agricultura y construcción, lo que contrasta con los demás grupos del Magreb.

Los datos comentados presentan hoy a los magrebíes en España como el grupo más numeroso de cuantos inmigrantes se asientan en el pais, formado, mayoritariamente por hombres jóvenes y activos, con un notable número de familias, en el que cada día resulta mayor la incorporación de mujeres al mercado laboral, que se ocupan en trabajos de poca cualificación, entre los que destaca la agricultura y construcción, seguidos del comercio, hostelería y servicios personales y que se distribuyen por buena parte del territorio, aunque con predominio en las áreas de Madrid, Barcelona, Levante y Andalucía. 


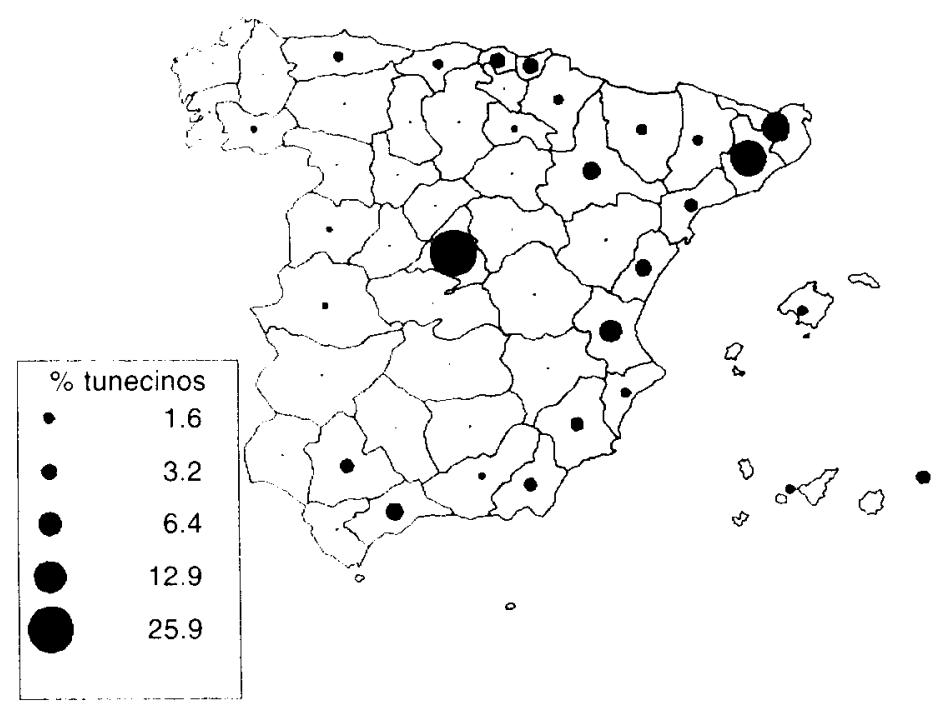

Figura 6c. Distribución trabajadores tunecinos. 31-XII-1993.

Por otro lado, y gracias a los ya numerosos trabajos que se han ido realizando y a nuestras propias experiencias, tenemos bastante información directa sobre las condiciones de vida y grado de integración del grupo en nuestra sociedad. La realidad es, como no podía ser menos, compleja y variada. En una gran ciudad como Madrid, por ejemplo, coexisten varias situaciones, desde grupos formados por familias asentadas, que viven en barrios de clase media-baja, a barrios de chabolas de infima calidad y grupos de hombres solos, que ocupan infraviviendas; con muy diferentes grados de integración, desde aquéllos que sí lo están, con los hijos escolarizados y hasta yendo a la Universidad, a los que no lo están en absoluto, sino que ocupan lugares de excepción entre los grupos más marginados de inmigrantes. En las áreas donde abundan los magrebies que trabajan en la agricultura hay numerosas muestras de situaciones de gran precariedad y penuria, sobre todo entre los grupos que están de forma clandestina, aceptando cualquier trabajo, sufriendo explotación y malviviendo.

\section{EL FUTURO DE LA INMIGRACIÓN MAGREBI}

Llegados a este punto tras este panorama general,vamos a dedicar la última parte al futuro. ¿Es previsible el futuro? Ciertamente no lo es, por ello no vamos a predecir nada, sino a tratar algunos puntos en relación a lo que puede ocurrir, con carácter de mera reflexión. 
En la puesta en marcha de un proceso migratorio, entran en juego razones o causas variadas, que tienen que ver con el lugar de origen y también con el de destino. La situación de los países del Magreb es la causa inicial que fuerza a la población a salir, pero no es la única. Hagamos algunas observaciones.

\section{LAS DIVERSAS CONDICIONES EN ORIGEN Y DESTINO}

Como dice Bernabé López, la emigración magrebí hacia el extranjero es la simple consecuencia de la presión de tres factores, unas estructuras agrarias inadecuadas, la escasez de empleo y un marco político y social opresivo.

El campo magrebí sigue siendo fuente de un continuo éxodo rural, como consecuencia, en parte, de que la fecundidad es alli el doble que en las ciudades $y$, en parte también, porque las condiciones de vida siguen marcadas por el arcaismo absoluto. Este éxodo rural no puede ser absorbido, además, por las ciudades de la región, que no pueden ofrecer medios de vida, ni siquiera a sus propias poblaciones.

En el Magreb, en razón de la juventud de su población (vid cuadro 6 , menores de 15) llegan anualmente al mercado de trabajo del orden de 600.000 jóvenes, que van a engrosar, directamente, las listas de desocupados y son candidatos a una emigración que cada dia tropieza con más obstáculos para acudir a los lugares tradicionales de acogida en Europa.

Otro factor importe es el psicológico. La población de estos países ve frustradas sus aspiraciones a la modernización y a la movilidad social, insatisfechas por las estructuras tanto políticas como sociales, en su lugar de origen. Para muchos de ellos, Europa, Occidente, hacia donde sienten un rechazo ideológico al identificarlo como el antiguo opresor de la época, aún reciente, de la colonización, es, a la vez el foco de atracción que ejerce una fascinación.

No hay que olvidar tampoco que para Europa la inmigración, a pesar del paro que hoy ensombrece el panorama, también ha constituido, y aún constituye una necesidad. No podemos olvidar que hay un envejecimiento de la población, una nueva flexibilización del mercado de trabajo, exigencia de competitividad y como resultado hay trabajos que no se cubren con los nativos. Esto también afecta a España, donde falta mano de obra para la agricultura, en las zonas de agricultura intensiva, para el servicio doméstico, etc.

Por otro lado, aunque la emigración es un hecho traumático, que nadie pone en duda, en realidad tiene para la economía del país de origen ventajas de fondo considerables. No se puede olvidar que para un país como 
Marruecos las remesas de los emigrados a Europa suponen un $46 \%$ de sus rentas de exportación, con lo que puede hacer frente a su déficit comercial.

CUADRO 6. SITUACIÓN DEMOGRÁFICA Y ECONÓMICA, ESPAÑA Y MAGREB

\begin{tabular}{lrrrr}
\hline DATOS & MARRUECOS & ARGELIA & TÚNEZ & ESPAÑA \\
\hline Población estimada 93 & 28,0 & 27,3 & 8,6 & 39,1 \\
TBN \% & 31 & 34 & 25 & 10 \\
TBM \% & 8 & 7 & 6 & 9 \\
Crecimiento anual \% & 2,4 & 2,7 & 1,9 & 0,1 \\
Duplicación pobl/año & 29 & 26 & 36 & 578 \\
Proyección 2010 & 38,1 & 38,2 & 11,3 & 38,9 \\
Proyección 2025 & 46,3 & 46,8 & 13,4 & 36,4 \\
T. Mortalidad inf. (a) & 57 & 61 & 43 & 7,8 \\
Tasa Fertilidad (b) & 4,2 & 4,9 & 3,4 & 1,3 \\
\% Menores 15 años & 40 & 44 & 37 & 19 \\
\% Mayores 65 años & 4 & 4 & 5 & 14 \\
Esperanza vida nacto. & 65 & 66 & 68 & 77 \\
Esperanza vida hombres & 64 & 65 & 67 & 73 \\
Esperanza vida mujeres & 67 & 67 & 69 & 80 \\
Población urbana \% & 47 & 50 & 59 & 78 \\
Validez datos (c) & $\mathrm{B}$ & $\mathrm{B}$ & $\mathrm{B}$ & $\mathrm{A}$ \\
\% muj. uso anticoncep & 42 & 36 & 50 & 59 \\
Idem modernos métodos & 36 & 31 & 40 & 38 \\
Opinión gobierno nivel fertilidad (d) & $\mathrm{H}$ & $\mathrm{H}$ & $\mathrm{H}$ & $\mathrm{S}$ \\
PNB p/cápita \$ 1991 & 1030 & 2020 & 1510 & 12460 \\
Superficie estado (e) & 446,3 & $2.381,7$ & 163,6 & 504,7 \\
Densidad hab/km² & 62,7 & 11,5 & 55,4 & 78,3 \\
PNB p/cápita \$ 1989 & 900 & 2170 & 1260 & 9150 \\
T. media crecimiento & 1,3 & 0,0 & 0,6 & 2,4 \\
PNB \% 1980-1989 & 7,4 & 5,2 & 7,5 & 9,4 \\
T. media inflación 1980-1989 & & & & \\
& & & &
\end{tabular}

\footnotetext{
(a) muertos por 1.000 nacidos vivos.

(b) media de niños nacidos por mujer durante su vida.

(c) $A=$ completos $D=$ inexistentes o incompletos.

(d) $\mathrm{H}=$ demasiado alto $\mathrm{S}=$ satisfactorio.

(e) miles de $\mathrm{Km}^{2}$.
}

Fuente: Population Reference Bureau. World Population Data Sheet. 1993.

Un análisis del cuadro 6 de datos demográficos y económicos comparativos del Magreb y España muestran el contraste entre estos países, 
que resulta bastante elocuente. Todos aquéllos poseen una población que está teniendo un rápido crecimiento. Si hoy es menor que la española, según las proyecciones realizadas para los años 2010 y 2025, si las cosas siguen igual, será bastante más elevada y, desde luego, muchísimo más joven. Esta población sigue siendo, en gran número, rural (vid la tasa de población urbana), en un campo que los va expulsando hacia unas ciudades, que no los pueden absorber. Otros indicadores son muy elocuentes: PNB, tasa de crecimiento del PNB, menores de 15 años, fertilidad, etc.

En estas condiciones se comprende que las cosas funcionen, un poco, a la manera de los vasos comunicantes, y tanto más cuanto más próximos estén los paises y cuanto mayor va siendo la información. Así, es previsible que no sólo no se frene, sino que se acreciente en gran medida el potencial migratorio del Magreb. Por otro lado, los países europeos, y ya también España, vieron hace tiempo el peligro que suponia para su futuro tener esta presión a las puertas y comenzaron a poner barreras, que impidieran lo que por algunos se ha considerado la "avalancha" que podía venír encima.

España tiene una posición especial en este contexto. A pesar de que, en relación a los países más avanzados de la Unión Europea, su situación no es buena (por ejemplo registra las tasas más elevadas de paro y está por debajo en múltiples indicadores), goza de una situación próspera y ha reiniciado su crecimiento económico, tras la última crisis, aún no cerrada. Además, está situada muy próxima, permite un fácil acceso y posee una tradicional economia sumergida, que la hacen especialmente atractiva para la inmigración clandestina.

España ha puesto en marcha un proceso que, de alguna manera, tiende a la contención de la inmigración. Se inició con la llamada "ley de extranjeria" de 1985 y ha tenido en el establecimiento de visados para algunas nacionalidades (concretamente a los magrebies) y en la fijación de cuotas, su más reciente manifestación. Además trata de mejorar su sistema de control y vigilancia, para evitar la llegada de clandestinos. Todo ello, sin duda, dificulta la entrada espontánea, pero, en el momento actual, es evidente que no la frena. El deseo de acudir a España no ha disminuido, a pesar de las dificultades con que aquí se encuentran los inmigrantes, como hemos visto en el caso de los marroquíes que habitan chabolas.

\section{EL INCIERTO FUTURO}

Con este panorama ¿Qué podemos pensar? ¿Qué va a ocurrir? Pues bien, lo que parece más fácil de pronosticar es la evolución de la población. Se han publicado algunos estudios al respecto. Los de Nadji Safir y Rafael 
Puyol destacan los profundos desequilibrios demográficos entre las dos orillas del Mediterráneo, que son de especial interés en razón de los movimientos de población del Sur al Norte, que pueden provocar.

El cuadro 7 muestra las perspectivas de población del conjunto de paises del Mediterráneo Occidental. De él se deducen tres tendencias:

1) Fuerte aumento de la población en los países de la Unión del Magreb Arabe, que se prevé puede rondar los 127 millones de habitantes en el año 2025.

2) Un relativo estancamiento en la población de los cuatro países mediterráneos de la Europa Occidental, que quedaría estabilizada en torno a los 170 millones de habitantes en el 2025.

3) Una progresiva reducción de las diferencias de las cifras de los dos grupos, que implica una notable modificación de los actuales equilibrios demográficos.

\section{CUADRO 7. PERSPECTIVAS DE POBLACIÓN EN EL MEDITERRÁNEO OCCIDENTAL}

\begin{tabular}{|c|c|c|c|c|c|c|c|c|c|}
\hline PAÍS & 1985 & 1990 & 1995 & 2000 & 2005 & 2010 & 2015 & 2020 & 2025 \\
\hline Argelia & 21.699 & 25.364 & 29.306 & 33.247 & 37.055 & 40.685 & 44.169 & 47.502 & 50.591 \\
\hline Marruecos & 22.120 & 25.139 & 28.274 & 31.366 & 34.254 & 36.977 & 39.568 & 41.953 & 44.368 \\
\hline túnez & 7.261 & 8.169 & 9.019 & 9.821 & 10.557 & 11.273 & 11.943 & 12.625 & 13.284 \\
\hline Libia & 3.786 & 4.544 & 5.445 & 6.500 & 7.695 & 8.977 & 10.278 & 11.571 & 12.846 \\
\hline Mauritania & 1.766 & 2.024 & 2.329 & 2.685 & 3.096 & 3.545 & 4.027 & 4.508 & 4.962 \\
\hline \multirow[t]{2}{*}{ Total parcial (1) } & 56.787 & 65.418 & 74.575 & 83.847 & 92.911 & 101.737 & 110.293 & 118.494 & 126.473 \\
\hline & 100 & 116 & 132 & 148 & 164 & 179 & 195 & 209 & 223 \\
\hline Francia & 55.170 & 56.173 & 57.188 & 58.196 & 58.889 & 59,430 & 59.867 & 60.229 & 60.442 \\
\hline Italia & 57.128 & 57.322 & 57.591 & 57.881 & 57.771 & 57.290 & 56.598 & 55.785 & 54.919 \\
\hline España & 38.602 & 39.333 & 40.060 & 40.812 & 41.420 & 41.831 & 32.102 & 42.366 & 42.530 \\
\hline Portugal & 10.157 & 10.285 & 10.429 & 10.587 & 10.717 & 10.809 & 10.873 & 10.912 & 10.935 \\
\hline \multirow[t]{2}{*}{ Total parcial (2) } & 161.057 & 163.113 & 165.268 & 167.476 & 168.797 & 169.360 & 169.440 & 169.292 & 168.826 \\
\hline & 100 & 102 & 103 & 104 & 105 & 106 & 107 & 106 & 105 \\
\hline Grecia & 9.934 & 10.047 & 10.124 & 10.193 & 10.247 & 10.249 & 10.201 & 10.139 & 10.080 \\
\hline
\end{tabular}

(1) Magreb.

(2) Países europeos/Mediterráneo occidental.

Fuente: Proyecciones de población mundial de la Naciones Unidas. 1988 Populations Studies, num. 106, 1989.

Además, hay que considerar que los países europeos están englobados en el contexto del resto de la Unión Europea, cuya población se prevé que para el 2020 haya disminuido en total con respecto al presente. 
En este trabajo se ve a la Unión Europea como en riesgo de funcionar como una bomba de aspiración de las poblaciones del Sur, atraídas por su prosperidad y que va a tener necesidad de mano de obra cualificada, para mantener su crecimiento y afrontar la competencia mundial.

Pero ¿Se cumplirán estas perspectivas? No somos muy favorables a las proyecciones. El entramado de las relaciones internacionales es sumamente complejo y surgen, continuamente, nuevos elementos que pueden modificar el futuro. Si en 1965 se hubieran hecho unas previsiones semejantes con España, Italia, Grecia y Turquía, en un lado y Bélgica, Gran Bretaña, Alemania Federal (entonces) y Francia, en otro ¿no se habría pensado que para 1995 la situación sería también de desequilibrio absoluto y de avalancha del Sur al Norte de Europa? ¿Cómo pronosticar entonces la crisis del petróleo, la caída del muro de Berlín, la reunificación de Alemania, la caída de los sistemas socialistas, el auge económico de España...?

Ahora mismo conocemos una situación concreta y es muy probable que, efectivamente, se aumente la presión del Sur sobre el Norte. En realidad, como hemos visto, para España el fenómeno no ha hecho más que empezar y seguramente continuará, a pesar de los cambios que se están llevando a cabo en política inmigratoria, pero también es cierto que entran en juego nuevos factores.

Los factores pueden ser muy diversos, unos de carácter global y otros particulares, que se relacionan con las dos partes que nos ocupan. Hoy, mucho más que en el pasado, los grandes acontecimientos mundiales afectan a todos los países, de modo que un cambio en el orden mundial podría ser, sin duda, desencadenante de cambios esenciales.

Por descontado pueden producirse cambios importantes que afecten a la economía de los países de Occidente, entre los que está España y también en los países árabes, y entre los factores particulares pueden ocurrir infinidad de cosas.

Vamos, no obstante, a apuntar algunos temas que están ya sobre la mesa y que pueden modificar la tendencia actual, en lo relativo a las migraciones Magreb-España. Sin duda, es esencial la evolución que puede tener la situación de los países del Magreb, que está en proceso de transformación. En este sentido me parece muy interesante y oportuno comentar el trabajo de algunos expertos del Centro de Estudios Prospectivos y de Informaciones Internacionales de Paris (Veronique Kessler). En su opinión en estos paises en los últimos años ha crecido la exasperación de la población, lo cual se manifiesta en numerosos conflictos internos, descontento hacia los países de Occidente y emersión 
de claras desmarcaciones culturales y sociales respecto al modelo occidental, que se vieron agudizadas tras la crisis del Golfo y que hoy están aflorando con fuerza...

Haciendo un ejercicio de simplificación los principales problemas con que se enfrentan estos países son, por un lado, un elevado endeudamiento exterior y una gran fragilidad de sus cuentas exteriores. Por otro lado, en el plano interno el principal problema es su fuerte ritmo de crecimiento demográfico, lo que conlleva que las necesidades sociales (atención a la salud, educación, etc.) ejerzan una tremenda presión sobre los presupuestos. Y, por descontado, como no podría ser menos, el paro y el subempleo, que no son desconocidos tampoco en Occidente.

Las economías de los paises árabes han sufrido las consecuencias de la crisis mundial con una notable disminución de su crecimiento económico, que han puesto de manifiesto su gran dependencia frente al exterior.

Tras la independencia, por otro lado muy reciente, en estos paises se habia desarrollado un modelo en que el Estado dirigía toda la actividad productiva y financiera, estando la iniciativa privada bastante atrofiada. El Estado tenía que desarrollar la base productiva y, a la vez, satisfacer las necesidades de la población creciente y dió lugar a una política proteccionista, en la que el grado de competencia era nulo. La situación se hizo insostenible y las economías magrebíes se vieron forzadas a introducirse en la rueda de la economia mundial, iniciando un proceso de liberalización. Este proceso está hoy en marcha y es el factor a que nos referiamos, que será esencial para la evolución futura.

El proceso de liberalización se lleva a cabo con una serie de reformas que se van iniciando y se siguen con diferencias de unos países a otros. Todos ellos, no obstante, y aunque también con diferencias, se han visto en situaciones de grave endeudamiento, que van gestionando, pero que va a pesar por mucho tiempo.

Las reformas emprendidas van en la doble línea de tratar de conectar la economía del país con la economía mundial, abriéndose a la competencia exterior y al capital extranjero, y de tender a liberar al Estado, devolviendo a la política monetaria su autonomía frente a las necesidades del Tesoro y volviendo a las leyes del mercado y de fomento del dinamismo del sector privado.

El pais pionero en emprender las reformas ha sido Marruecos, con el apoyo del FMI y del Banco Mundial, pudiéndose poner el punto de partida en la modificación de la Ley de Presupuestos de 1983. Argelia y Túnez, en 
cambio, no iniciaron sus reformas hasta que se encontraron con el shock del petróleo de 1986. Las reformas emprendidas son:

a) Introducir las reglas del mercado en la reglamentación financiera de la economía. Son medidas de gran envergadura y que se siguen a distinto ritmo en los tres paises.

b) Reformas fiscales, que buscan dotar al Estado de nuevos medios para equilibrar sus cuentas. En Marruecos está ya prácticamente concluida la reforma fiscal, que, no obstante, tiene numerosos problemas, como la resistencia de los poderosos a perder sus privilegios y que el terreno favorito del impuesto son las rentas medias y modestas, el consumo de masas y la persistencia de mucha economía sumergida. En Túnez y Argelia también está avanzada la reforma fiscal y es muy grande, igualmente, la economía sumergida.

c) Reformas en los régimenes aduaneros, que consisten básicamente en liberalizar la importación y en estimular la exportación.

d) La liberalización de precios es otra medida clave, encaminada a restaurar la competencia interior, lograr la mejora de la productividad y estimular la producción. Estas medidas han provocado delicados conflictos, que se han ido solventando porque los incrementos de los precios han sido comedidos. En Argelia, no obstante, la mala organización de los circuitos de distribución internos, han provocado verdaderas situaciones de penuria.

e) Medidas encaminadas a reactivar la inversión privada y a atraer capital extranjero. En Marruecos, por ejemplo, se favorece sobre todo la inversión en el medio rural y en el turismo.

f) Por último, la privatización de empresas públicas que resulta clave en todo proceso de liberalización y que encuentra muy serios obstáculos en estos paises.

Por tanto, están en marcha una serie de reformas, que a los españoles no nos resultan extrañas, pues se ha vivido un proceso con ciertas similitudes. Pero todavia son incipientes y tropiezan con muchas dificultades y aún hoy es difícil juzgar el impacto que van a tener para dinamizar los agentes económicos y restaurar los equilibrios.

Los expertos reconocen que las medidas tomadas son importantes, de gran amplitud y que, aunque necesiten corrección y mejora, se puede afirmar que la revolución de los aparatos económicos está en marcha y tendrá que dar sus frutos. Para muchos se ha emprendido una carrera de velocidad pero ¿Cómo avanzará? 
El ajuste se lleva acabo a dos niveles, uno estructural, con las reformas y otro coyuntural, con políticas de austeridad. Ahora bien, la política de austeridad que se impone a la población, si no hay claras mejoras, puede hacerse insufrible, con una degradación de los niveles de vida y unos desarreglos en los aparatos productivos y distributivos muy graves. Si la situación económica, política y social se degradan demasiado, será muy difícil mantener el ritmo de la liberalización. Además, no hay que olvidar que la situación afecta a una población muy joven, con una gran crisis de identidad, que necesita situarse en el mundo, encontrar su camino y crearse una ideología (que no será necesariamente la del mundo capitalista y que puede ser dual, unos hacia Occidente y otros hacia el integrismo). Si se les hace esperar mucho estarán dispuestos a movilizarse.

La situación, por tanto, es delicada. Hay visos de cambio. Occidente, Europa, temerosa de la presión cercana de estas poblaciones es consciente y por ello está dispuesta a apoyar el proceso de liberalización y, de hecho, hay ayudas del FMl y del BM y se producen inversiones, pero el futuro es incierto.

Para los observadores y expertos está claro que a todos nos interesa estimular el co-desarrollo del Mediterráneo Occidental. Para que los países del Magreb mejoren su situación han de insertarse bien en la economía mundial. Para ello, deberán aprovechar sus ventajas específicas para amarrarse en el mercado mundial, pero todos sabemos que esto no es fácil. La carrera está en marcha y son muchos los contrincantes que luchan por estar bien situados. Hay que elegir bien los socios y espabilarse para estar en los mercados en punta, lo que es muy difícil.

Para estas economías, además, la apertura plantea problemas. Se hacen más vulnerables, por ejemplo ante los movimientos de la demanda, que puede fluctuar con facilidad.

Pero nuevos obstáculos surgen en el camino. Así, tenemos que un elemento clave para lograr unas mejoras en la economia, aprovechando algunas de las ventajas especificas es, por ejemplo, el desarrollo del turismo. De hecho es considerado como un instrumento de futuro para el Magreb, tal como expresaba Jesús A. Núñez Villaverde. En Marruecos, donde está más avanzado, desde 1983 cuenta con un código de inversiones en turismo, que sienta las bases para incentivar todo tipo de actividades turísticas y otorgar al turismo el mismo trato que al sector de exportación en cuanto a ventajas crediticias y fiscales. En Túnez tiene un notable desarrollo, suponiendo alrededor del 30\% de todas las entradas en divisas en 1990.

Este asunto no es baladi y sin duda tiene futuro (en España algo sabemos de eso). En cambio hay algunos elementos nuevos que entran en 
juego y pueden hacerlo peligrar, además de que se enfrentan, aún, a múltiples problemas entre los que cabe señalar, el escaso nivel de ahorro nacional, que hace depender al sector del capital extranjero, el bajo nivel de turismo nacional, que crea dependencia del mercado exterior, la inestabilidad política permanente, que hace que la demanda tenga vaivenes periódicos, con recesión de visitantes y la falta de infraestructuras de todo tipo, sobre todo de una red de comunicaciones adecuada.

Por otro lado, a todos se nos viene a la cabeza el problema que cada día vemos en la prensa. El fundamentalismo islámico está desarrollándose con fuerza, sobre todo en Argelia, donde la situación es realmente preocupante. No vamos a entrar en cuestiones políticas, pero no podemos olvidar que el desarrollo de estos países no tiene sólo el frente económico. Para llegar a él será precisa una democratización social y política y la corrección de los fuertes desequilibrios.

La evolución de esta cuestión va a ser, sin duda, decisiva en los tiempos venideros, por lo que las conjeturas son muy aventuradas.

Pero hay, además, otros muchos factores en juego. No hemos mencionado la importancia que tiene y puede tener en el proceso de liberalización económica y de cooperación, la cuestión de los países del Este, que tienen en marcha su propio proyecto de liberalización económica y que son un serio competidor, al que Europa ha de prestar, también, mucha atención y ayuda.

Los países del Este afectan de muchas formas, en concreto también en el tema de la emigración. En los últimos años hubo voces que pronosticaron una posible "avalancha" de gentes del Este con destino a Occidente. No ha sido así. Hay un flujo importante, pero no lo que se auguró. A España, en concreto, se ha creado un flujo, que no es grande. Hay, en la actualidad, en torno a 6 ó 7.000 personas «legalmente», más un número no bien conocido de clandestinos, procedentes de estos países, sobre todo de Polonia (el $50 \%$ ), que resulta importante y que está en auge. Sin duda, además, estos inmigrantes, más cualificados y mejor acogidos por la población, y dispuestos a realizar cualquier tipo de trabajo, son una competencia que afecta al inmigrante magrebí.

Hemos mencionado diversos factores que pueden actuar a favor y en contra del mantenimiento (acrecentamiento o disminución) del flujo migratorio Magreb-España. Otro factor es el que puede resultar del desarrollo de una postura cada vez más extendida. Por diversos motivos hay muchas voces que claman porque se ayude a los pobres (recordemos la campaña del 0,7$)$, unos por la idea de remediar la tremenda injusticia, otros por pensar, incluso, que si no se actúa iya! las cosas pueden tener consecuencias 
imprevisibles. La presión de una población pobre, muy joven y que crece a fortísimo ritmo, frente a unas puertas que intentan echar el cerrojo, tras de las que hay una población envejecida y rica, que también tiene sus problemas, no se puede mantener con la válvula puesta.

Muchos pensamos que las cosas están en un punto en que hay que actuar; lo deseable es que la gente no tenga que emigrar porque la miseria y la necesidad los empuje. Al tiempo lo deseable es que quien lo quiera tenga la libertad de acudir alli donde pueda encontrar lo que necesite.. Pero si esto es lo deseable, no creo que sea lo previsible en el futuro cercano. (La reciente Conferencia sobre la pobreza, celebrada en Copenhague en marzo de 1995, ha vuelto a poner sobre la mesa la necesidad de que los paises ricos actúen para ayudar a los pobres).

En los años venideros, siempre que no haya grandes cambios que generen transformaciones, parece previsible que continúe la emigración del Magreb a España, cuando menos al ritmo que impongan las cuotas y medidas restrictivas del Gobierno español, que no puede permitirse la libertad en las fronteras, ni por sus propias posibilidades (no olvidemos nuestra tasa de paro), ni por las imposiciones de la Unión Europea, que teme que España, por su proximidad a Africa, se convierta en una puerta fácil de franquear.

Entretanto no llegue a "despegar» la economía de los países del Magreb (y no olvidemos que detrás están los aún más pobres de los países subsaharianos), el flujo seguirá y, en parte, será clandestino.

Lo que hemos de esperar es que si se ponen los medios, llegue a producirse la mejoría y se asista a un cambio como el que hemos conocido en España, que, como deciamos al comienzo, en un período reciente pasó de emisor a receptor y a que se logre que los que se desplacen, o los que ya lo han hecho, lleguen a una mayor integración, camino en el que aún queda mucho por hacer.

\section{CONCLUSIÓN}

En cualquier caso todo son conjeturas. En España también han de producirse algunos cambios en el futuro, pero probablemente sobre las bases que se han sentado recientemente. El país ha empezado a asimilar el haberse convertido en receptor de inmigrantes y ha comenzado a adecuar mecanismos. Ya no tenemos un Instituto Español de Emigración, sino una Dirección General de Migraciones. Se mejora la estadística de extranjeros y se toma conciencia del problema de la integración (esto no quiere decir 
que se resuelva). Los ayuntamientos afectados por problemas de chabolismo o de brotes de xenofobia, toman medidas para intentar paliarlos, como la puesta en marcha de planes de realojo de población marginal, alquileres de vivienda, ampliación de servicios sociales, etc.

La propuesta más reciente ha sido la implantación de cupos, además del visado para algunos países, que va dirigida a evitar el crecimiento incontrolado. Pero hay presión en la calle para que se realicen otros cambios. Se siguen produciendo manifestaciones en apoyo de la modificación de una ley que algunos consideran racista y de que se den más facilidades para la integración.Y, además, ya se han anunciado cambios en las disposiciones actuales.

Por tanto, estamos inmersos en un proceso que ya no es nuevo y que es previsible continúe por mucho tiempo. En concreto, pese a todo lo que hemos dicho, que puede hacer tomar nuevos rumbos a la situación, parece que los países del Magreb, aunque están iniciando cambios demográficos, van a tener una gran presión y no se puede ser excesivamente optimista en cuanto a que logren absorber su propia población que anualmente llega al mercado de trabajo. Los cambios que se esbozan, si no son abortados por los conflictos internos que puede generar el integrismo emergente, sólo con la ayuda y la cooperación desde los países ricos podrán llegar a realizarse.

\section{BIBLIOGRAFIA}

COLECTIVO IOE (1987): Los inmigrantes en España. Revista de Estudios Sociales y de Sociología Aplicada. Cáritas Española. Madrid. 376 pp.

Chevalief, A., Kesslen, V. (1989): Economies en développement et défis démographiques: Algérie, Egypte, Maroc, Tunisie. Notes et Etudes Documentaires, n. 4878. Paris. La Documentation Française.

- (1990): Contrastes demográficos y empleo en el Mediterráneo Occidental: un desafío for. midable. Información Comercial Española, n. 683. pp.14-28.

DRISS, B.A. (1991): La economia marroqui en busca de nuevo aliento. Información Comercial Española, n. 2283. pp.1.929-1.933.

Gómez López, J.D., Segrelles Serrano, J.A. (1993): La situación de la mano de obra marroqui en los invernaderos del Campo de Dalías (Almeria). IV Jornadas de la Población Española. La Laguna.

González YanCi, M.P. (1995): La emigración de marroquies a España. Actas II: Congreso Internacional. El estrecho de Gibraltar. Noviembre 1990, tomo III, pp. 355-378.

Gozalvez PÉrez, V. (1993): Inmigrantes marroquíes y senegaleses en Alicante y Castellón. IV Jornadas de la Población Española. La Laguna.

KESSLER, V. (1991): El futuro económico de los países del Magreb. Información Comercial Española, n. 698. pp.153-172.

LOPEz GaRciA, B. (1992): Las migraciones magrebies y España. Alfoz, pp. 52-59

- (1989) Política y movimientos sociales en el Magreb. CIS Madrid.

MARTin Muñoz. G. (1991): Transformaciones políticas en el Norte de Africa: ¿un modelo áraboislámico de transición? Información Comercial Española, n. 2283. pp.1909-1915. 
MazarRasa, A.(1991): La cooperación con los países del Norte de Africa. Información Comercial Española, n. 2283. pp.1910-1908.

NADJI SAFIR (1991): Factores demográficos en el Mediterráneo Occidental. Información Comercial Española, n. 2283. pp.1916-1921.

NÚNEZ VILLAVERDE, J. (1991): El turismo en el Magreb: un instrumento de futuro. Información Comercial Española, n. 2283. pp.1957-1963

Pumares, P.: La inmigración marroquí en la Comunidad de Madrid. Tesis doctoral. (1994).

Purol antolín, R. (1991): Evolución demográfica de los países riberenos del Mediterráneo. Economía y Sociología del Trabajo, n. 11. pp 61-71.

RoselLó, J.L. (1991): Relaciones económicas entre España y Marruecos. Información Comercial Española, n. 2283. pp.1980-1985.

VIDAL DOMINGUEZ, M.J. (1992): Movilidad espacial del colectivo: ¿Madrid, ciudad de tránsito o de permanencia? España-Magreb siglo XXI: el porvenir de una vecindad. Madrid MAPFRE. pp.335-356.

Viruela MaRTinez, R. (1993): Condiciones de vida y de trabajo de los magrebies en España: marroquies en la provincia de Castellón. IV Jornadas de la Población española. La Laguna. pp.S47-556.

- (1992): El Magreb: crecimiento demográfico, empleo y emigración. Saitabi, n. XLII. pp.315337. 